\title{
Nacionalismo, esportes e TV, uma reflexão sobre significados: entrevista com Marco Roxo
}

\section{Ciro Augusto Francisconi Götz}

Doutorando; Pontifícia Universidade Católica do Rio Grande do Sul, Porto Alegre, RS, Brasil cirogotz@gmail.com

\section{Resumo}

Nesta entrevista, o professor doutor e mestre em Comunicação pelo Programa de Pós-Graduação em Comunicação da Universidade Federal Fluminense, graduado em Comunicação Social/Jornalismo pela mesma universidade, Marco Roxo, discorre sobre formatos e os múltiplos significados associados à mediatização de grandes eventos esportivos por emissoras de TV. Durante o período de Copa do Mundo Fifa de futebol masculino, umas das questões que volta à discussão é a da nacionalização. Sendo assim, torna-se importante refletir sobre a autoridade jornalística e seu papel na mediação.

\section{Palavras-chave}

Comunicação Social. Jornalismo. Televisão. Esportes. Nacionalismo.

Em ano de Copa do Mundo da Rússia, questões como o nacionalismo vêm à tona - e este é, também, um período fértil para estudos e reflexões sobre as narrativas dos meios de comunicação, no âmbito do cada vez mais ágil desenvolvimento tecnológico. No caso específico da televisão, seria esse ainda um meio "autoritário"? Tal posição, se verdadeira, é replicada, de alguma forma, no recorte das transmissões esportivas? Para entender essas questões, conversamos com o doutor e mestre em Comunicação pelo Programa de PósGraduação em Comunicação da Universidade Federal Fluminense (UFF) Marco Roxo, graduado em Comunicação Social/Jornalismo pela mesma universidade. Roxo atua como professor adjunto do Departamento de Estudos Culturais e Mídia do Instituto de Arte e Comunicação social da Universidade Federal Fluminense (IACS-UFF). A entrevista aconteceu durante o seminário intitulado Televisão, Esportes e Nacionalidade, promovido pelo 
Programa de Pós-Graduação em Comunicação Social da Pontifícia Universidade Católica do Rio Grande do Sul (PUCRS) em maio de 2018, antes da Copa do Mundo da Rússia. 0 centro de sua pesquisa aborda a questão da autoridade jornalística e o seu papel na mediação da experiência esportiva. Seus estudos têm como grande meta a discussão do impacto de estratégias no tempo e no crescimento dos programas jornalísticos sobre esporte na grade. Por fim, propõe reflexão sobre os canais esportivos segmentados, ou por assinatura. Acompanhe.

Neste seminário, o senhor propôs a discussão de formatos e os múltiplos significados associados à mediatização de grandes eventos esportivos pela televisão. Existe um momento histórico em que podemos definir que a televisão se consagrou como atributo da cultura popular contemporânea? Isso aconteceu mais em função da popularização do aparelho ou do papel desempenhado pela mídia?

Marco Roxo: Contemporânea, bem, eu acho que sim. A televisão tem um desenvolvimento histórico interessante, mas pouco desenvolvido. Principalmente porque ela envolve pesquisas de matrizes históricas, mas relacionadas a um regime de temporalidade um pouco maior. Para você entender um pouquinho das mudanças relacionadas ao aparato e às tecnologias televisivas e, de certa forma, como essas tecnologias se desdobram na construção ou na reinvenção de certos programas que vão se desdobrar na grade. Então, o que a gente chama de mediatização é isso, é a formação de novos circuitos comunicativos que vão envolver o que a gente chama de "TV de Segunda Tela", que são os aplicativos, os aplicativos móveis, tablets, celulares, o próprio computador e a relação disso com os processos de transmissão esportivas. E, obviamente, é claro que, se você pega, por exemplo, um campeonato com a Champions League, vamos dizer, a formação de ídolos, o processo de idolatrização de determinados personagens que vão se transformar em ídolos mundiais, associados à prática esportiva, não apenas no futebol, mas em outras como atletismo, natação e outras modalidades, em torno das quais, a intensa circulação de imagens desses personagens vão transformá-los em celebridades mundiais. Então, a gente tenta trabalhar com alguns eixos metodológicos que nos permitam propor e desenvolver eixos de pesquisa que possam abarcar esse fenômeno. Por isso que o trabalho envolve entender a correlação desses processos com discussões acerca da nacionalidade, que é um 
tema relativamente presente na ideia de prática esportiva, como uma espécie de soft power, a forma como as nações se apresentam ao mundo, durante esses jogos. Olimpíadas, Copas do Mundo, Paralimpíadas, agora. Podemos trabalhar, também, pensando nos processos relacionados à transmissão, o uso intenso dos recursos de transmissão, a formação de programas de debate esportivo, o crescimento deles na rede e na própria televisão segmentada. Por último, a correlação que esses programas têm com aquilo que a gente chama de cultura popular, como essa cultura é atravessada como práticas relacionadas ao ver, ao torcer, e isso ativa um certo mercado consumidor. E consagrando a televisão e os programas associados a ela, dentro dessa ambiência massiva, associada à noção do papel que a audiência exerce na configuração do gosto televisivo. Então, são mais ou menos esses eixos que a gente procura trabalhar. É lógico que foi um seminário curto [e], em parte, trabalhar dentro desses eixos exige um exame bibliográfico um pouco mais profundo para que a gente consiga, em torno da bibliografia, pensar questões e formas metodológicas de poder desenvolvê-las.

Neste momento de convergência, a televisão ainda pode ser considerada um meio “autoritário"?

Marco Roxo: Bem, eu não sei o que você chama de "um meio autoritário", mas, de uma certa forma, eu acho que ela ainda conserva isso, porque a televisão trabalha com a questão do tempo. Então, o que significa? Significa que você vê as imagens em forma relativamente sequencial. É lógico que, no caso do esporte, o uso de recursos como replay, o slow motion, às vezes quebra um pouco uma certa sequencialidade narrativa. E, por outro lado, a noção de Segunda Tela te permite, enfim, ver o mesmo fenômeno sobre múltiplos olhares. Aquilo como é apropriado do aparato televisivo e, às vezes, passa a circular em outros aparatos, mas, às vezes, reconfigurados através do uso de recursos musicais, imagéticos, memes, et cetera e tal. Então, de uma certa forma, sim - muito embora porque conserva certos elementos associados às noções de imediaticidade e vivacidade, ou seja, são programações ao vivo, mas cuja repercussão e intenso processo de mediatização permitem replicá-las e guardá-las na memória, pós evento. 
Se realizarmos uma comparação na forma de narrativa, por exemplo, entre locutores brasileiros e ingleses, percebemos uma série de particularidades na maneira de se transmitir vamos usar aqui, para ilustração - um jogo de futebol. Essas narrativas, de fato, estão inteiramente ligadas à cultura popular? Além disso, é correto afirmar que existe uma narrativa ou um tipo de cobertura melhor do que outra? Certa ou errada?

Marco Roxo: Acho que toda narrativa, e se você pensar transmissão com uma espécie de um narrar, de um contar, elas variam porque estão associadas a padrões culturais relativamente distintos. Tem certos atributos do que a gente chama de nacionalidade. Isso pode perpassar tanto pela forma, como o processo de produção de imagens é configurado, quanto pelo uso da linguagem em vernácula. Esse é um aspecto. 0 segundo aspecto, que é a ideia da cultura popular, a gente tem que conceituar o que a gente entende por cultura popular. Então, a ideia, se você usar a noção de capital do Bourdieu, que ela não estaria ainda institucionalizada nem plenamente objetificada e, portanto, ela não tem ainda os mecanismos de consagração. Vamos dizer assim, que confiram a ela uma espécie de capital cultural, como um quadro exposto em um museu. Então, sim, porque está associado a um pouco, principalmente, o ver futebol: o lugar da televisão na mediação da nossa experiência esportiva com essa relação que nós temos com o tempo e com uma certa relação de lazer. A ideia de você ocupar o seu tempo livre, vamos dizer, vendo um jogo, construindo rituais em torno desse ver. Como é muito comum em relação, principalmente aqui no Brasil, em relação ao futebol. Então, isso estabelece hábitos, padrões de consumo, ativa mercados, promove múltiplas interações em torno das quais, se você pensa um pouco, a noção de nacionalismo. A gente está falando de uma modalidade de nacionalismo em torno da qual práticas comerciais, vendas de camisetas de futebol, hino, marcas esportivas, o desdobramento delas [ocorre], e que podem ser associadas a noções não stricto senso nacionais como o multiculturalismo, a diversidade. Isso pode estar presente na configuração de selecionados nacionais. Você pensa na Seleção Francesa. A relação de "não francesidade" de diversos jogadores, vários negros, vários vindos de diversos países da África, cuja nomenclatura, o nome e tal, dá esse tipo de conotação. E isso empresta a esse selecionado nacional um caráter multicultural. E, por outro lado, a prática, o próprio crescimento de uma prática com o turismo associado a ver esses jogos. Há múltiplos eixos de pesquisa que podem ser explorados em relação a esses fenômenos esportivos que eu não sei se são 
contemporâneos, mas cujo desdobramento, o alcance e essa correlação mais forte com o lazer e o entretenimento estão muito demarcados.

Sobre a questão de nacionalidade, de fato, a apropriação acontece em razão de uma consciência social (por exemplo, em períodos de Copa do Mundo) ou, por outro lado, o discurso faz parte de uma estratégia comercial?

Marco Roxo: Tem as duas coisas. 0 difícil é você dimensionar o grau. Não sei se há uma consciência nacional. Mas o pessoal trabalha um pouco com a ideia, no termo inglês, de nationhood. Não é propriamente a nacionalidade, mas é como essas narrativas da nacionalidade perpassam múltiplos discursos, tanto eles associados à competição quanto ao consumo. Aí voltam aquelas questões: consumos de camisas de clubes, de seleções, ativam um pouco esse viés de nacionalização. De outro lado, a própria ideia de exploração do território. Se você pensa nas Copa do Mundo na África [em 2010], no Brasil [em 2014], as estratégias que o governo brasileiro usou para espalhar os jogos por quase todo o território nacional, já que o Brasil é o "país do futebol", e não concentrados em determinada região, apontam essa correlação entre lazer, futebol e política, onde, volto a falar, a exibição do Brasil como nação entra em questão. E aí são categorias, uma das quais, a gente vai pensar, [são] os atributos políticos. Como a nação se vende? Com ela se vende? Como ela se expõe? Como se traduz através da cobertura que vai existir, através desses jogos?

Sobre a estrutura básica de uma transmissão, temos as figuras do narrador, repórter e comentarista. É possível identificar onde o jornalismo se confunde com o espetáculo? Existe algum limite para o jornalismo na relação entre essas funções, ou uma transmissão, pode-se dizer, é uma prática jornalística o tempo todo?

Marco Roxo: Eu acho que a transmissão é uma prática que foi apropriada pelo jornalismo. Há uma certa discussão acerca de a qual tipo de categoria pertencem os locutores, jogadores de futebol, profissionais que são convocados para comentar, exercer essa prática do comentário. Ela não é uma prática exclusiva de jornalistas, mas também é feita por jornalistas. Há programas de comentários que se autointitulam programas jornalísticos. É difícil de responder isso. Tem que ter um estudo mais sistemático, porque o 
comentário ainda é uma prática pouco problematizada, pouco discutida. E, portanto, há certos hiatos que não nos permitem responder essas perguntas com exatidão. É lógico que o comentário, na sua configuração histórica, não é apenas associado ao jornalismo esportivo. Você pensa, comentários políticos: eles são efetuados em alguns telejornais por políticos, mas, também, por cientistas políticos. Então, às vezes o uso dessa figura, alguns chamam "do especialista", referenda, sustenta o lugar de autoridade nos programas de mesa redonda. É preciso entender melhor, por exemplo, a presença desses "não jornalistas", de que forma ela é justificada, de que forma ela sustenta argumentos de autoridade. E, por último, isso, em um eixo sincrônico, comparando programas diversos. E no recorte mais diacrônico, como esses programas foram se configurando historicamente. Então são dois eixos de pesquisas que podem ajudar a organizar um pensamento sobre ele.

Para encerrar, existe alguma ameaça à televisão que conhecemos como tradicional? Como afirmam alguns "apocalípticos", a TV corre o risco de "morrer"?

Marco Roxo: É difícil porque a televisão meio que se multiplicou, e eu sou adepto à tese de que essas noções de vivacidade, de imediaticidade, a lógica do ao vivo, ainda sustentam muito daquilo que a gente entende por televisão. É lógico que isso não está mais associado à noção de broadcasting, apenas. A televisão de um para muitos. Mas ela, mesmo no narrowcasting, é dominada por franquias, internacionais e multinacionais que, pelo menos no campo esportivo, exercem algum grau de monopólio. E, a partir delas, se multiplicam várias formas de produção de conteúdo associado ao esporte, mas que negociam com aquilo que é apropriado a esses agentes dessas transmissões. Então, de uma certa forma, ela existe, mas, não é exatamente como a televisão dos anos 1970, anos 1980, associada à ideia da TV nacional, à formação das comunidades. Mas, sim, acho que a TV ainda existe. Essas noções de vivacidade e imediaticidade dão suporte a essa ideia de televisão de transmissão, de noção ainda de poucos para muitos. 


\title{
Nationalism, Sports and TV, a reflection on meanings: interview with Marcos Roxo
}

\begin{abstract}
In this interview, professor Marco Roxo, PhD and MSc in Communication from the Communication Postgraduate Program of the Universidade Federal Fluminense and also a Bachelor in Social Communications/Journalism from the same institution, addresses the formats and multiple meanings associated to the mediatization of big sports events on television. In times such as that of a World Cup, nationalisation is a question that rises once again. Thus it becomes important to reflect upon the journalistic authority and its role in mediation.
\end{abstract}

\section{Keywords}

Social Communication. Journalism. Television. Sports. Nationalism.

Recebido em 27/05/2018

Aceito em 17/06/2018 